\title{
Effects of five heavy metals at sub-lethal concentrations on the growth and photosynthesis of Chlorella vulgaris
}

\author{
OUYANG HuiLing, KONG XiangZhen, HE Wei, QIN Ning, HE QiShuang, WANG Yan, \\ WANG Rong \& XU FuLiu*
}

Laboratory for Earth Surface Process of Ministry of Education, College of Urban \& Environmental Sciences, Peking University, Beijing 100871, China

Received January 5, 2012; accepted February 6, 2012

\begin{abstract}
The impact of sub-lethal concentrations $\left(0.05,0.5,5 \mu \mathrm{mol} \mathrm{L}^{-1}\right)$ of the heavy metals copper $(\mathrm{Cu})$, chromium $(\mathrm{Cr})$, zinc $(\mathrm{Zn})$, cadmium $(\mathrm{Cd})$ and lead $(\mathrm{Pb})$ on the growth and photosynthesis of Chlorella vulgaris was studied during $96 \mathrm{~h}$ exposure experiments. The results showed that the effects of these five metals on the growth of Chlorella vulgaris were dependent on both concentration and exposure time. It was found that $5 \mu \mathrm{mol} \mathrm{L}{ }^{-1}$ treatments of $\mathrm{Cu}, \mathrm{Cr}, \mathrm{Zn}, \mathrm{Cd}$ and $\mathrm{Pb}$ significantly inhibited the growth of Chlorella vulgaris, and the effect became weaker with an increase in exposure duration. Different effects on chlorophyll fluorescence were found for different metals, with $\mathrm{Cu}$ and $\mathrm{Cr}$ having an inhibiting effect and $\mathrm{Zn}$ and $\mathrm{Cd}$ having a promoting effect. The effects of heavy metals upon the growth and photosynthesis of Chlorella vulgaris were independent of each other and not causally related.
\end{abstract}

heavy metal, sub-lethal, Chlorella vulgaris, growth, photosynthesis

Citation: $\quad$ Ouyang H L, Kong X Z, He W, et al. Effects of five heavy metals at sub-lethal concentrations on the growth and photosynthesis of Chlorella vulgaris. Chin Sci Bull, 2012, 57: 3363-3370, doi: 10.1007/s11434-012-5366-x

With the significant growth in both industry and urban development, the use of heavy metals has also risen, causing serious environmental problems in the water. Because algae play a role as primary producers in most aquatic ecosystems, estimating the effects of heavy metals on the growth and photosynthesis of algae can significantly impact the overall ecological risk assessment of heavy metals.

Heavy metals are highly abundant in nature. Among them, copper $(\mathrm{Cu})$ and zinc $(\mathrm{Zn})$ function as essential elements to plants while chromium $(\mathrm{Cr})$, cadmium $(\mathrm{Cd})$ and lead $(\mathrm{Pb})$ show little biological usefulness. $\mathrm{Cu}$ is not only a key component of electron transport chains but also of coenzyme factors that play important roles in plant photosynthesis and respiration [1,2]. $\mathrm{Zn}$ is a basic component of various enzymes involved in photosynthesis and metabolism, such as carbon anhydride, acidic phosphatase and alkaline phosphatase [3]. Plant growth is promoted once $\mathrm{Cu}$ and $\mathrm{Zn}$ are introduced into the plant's water supply. If lacking

*Corresponding author (email: xufl@urban.pku.edu.cn) either element, the plant's rate of growth and photosynthesis will be greatly reduced. However, both metals may become toxic at higher levels. Unlike $\mathrm{Cu}$ and $\mathrm{Zn}$, the heavy metals $\mathrm{Cr}, \mathrm{Cd}$ and $\mathrm{Pb}$ are not necessary for plant growth or respiration. However, with the rapid growth of industry, a great quantity of $\mathrm{Cr}, \mathrm{Cd}$ and $\mathrm{Pb}$ is being deposited into the water, resulting in adverse effects on plants. The toxicity of $\mathrm{Cr}$ is form-dependent, with $\mathrm{Cr}(\mathrm{VI})$ being the most toxic one [4]. $\mathrm{Cd}$, a potentially toxic metal that is very stable in aquatic environment, can directly affect the physiological processes of algae $[5,6] . \mathrm{Pb}$ is easily accumulated by algae and thus becomes a toxic influence [7].

The effects of heavy metal exposure upon algae manifest in suppressed cell division, inhibited growth rate, restrained enzyme activity and reduced photosynthesis [8-10]. Previous studies regarding the impacts of heavy metals on algae were mainly focused on finding the concentration that caused either $50 \%$ mortality ( $72 \mathrm{~h}-\mathrm{LC}_{50}$ or $96 \mathrm{~h}-\mathrm{LC}_{50}$ value) or $50 \%$ inhibition ( $72 \mathrm{~h}-\mathrm{EC}_{50}$ or $96 \mathrm{~h}-\mathrm{EC}_{50}$ value). Due to the development of chlorophyll fluorescence technology, it 
is now much easier to analyze the photosynthesis process, which has resulted in an abundance of new researches looking into factors that affect photosynthesis. Although the effects of heavy metals on algae have received significant attention and have been extensively studied, the exposure concentrations in those studies were necessarily high to calculate $\mathrm{LC}_{50}$ or $\mathrm{EC}_{50}$ values, and little information is available for evaluating the effects of these metals at sub-lethal concentrations.

In the present study, experiments were carried out on Chlorella vulgaris, a dominant type of green algae. Toxic effects of five heavy metals $(\mathrm{Cu}, \mathrm{Cr}, \mathrm{Zn}, \mathrm{Cd}, \mathrm{Pb})$ at sub-lethal concentrations $\left(0.05,0.5\right.$ and $\left.5 \mu \mathrm{mol} \mathrm{L}{ }^{-1}\right)$ on the growth and photosynthesis of Chlorella vulgaris were analyzed and compared, with the results intending to provide a more theoretical basis upon which to judge the toxic effects of heavy metals.

\section{Materials and methods}

\subsection{Algal material and culture conditions}

Chlorella vulgaris was chosen as algal material based on several considerations. Firstly, C. vulgaris is found all over the world and is a dominant type of green algae. Secondly, C. vulgaris is a suitable material for toxicity tests due to its simple growth conditions and strong tolerability. Finally, the results can be cross-referenced against a number of experiments where $C$. vulgaris has been used as the test algae.

C. vulgaris was provided by the Freshwater Algae Culture Collection of the Institute of Hydrobiology, the Chinese Academy of Sciences. It was cultured in BG11 medium at $(24 \pm 1)^{\circ} \mathrm{C}$ with a cycle of light $(14 \mathrm{~h}, 4000$ Lux $)$ and dark $(10 \mathrm{~h}, 0 \mathrm{Lux})$ in a GXZ-280B illumination cultivation cabinet (China). C. vulgaris was cultivated statically, put through a wave cycle two to three times and had its position changed randomly.

\subsection{Chemical materials}

Copper as $\mathrm{CuSO}_{4} \cdot 5 \mathrm{H}_{2} \mathrm{O}$ (analytical grade), chromium as $\mathrm{K}_{2} \mathrm{CrO}_{4}$ (analytical grade), zinc as $\mathrm{ZnCl}_{2}$ (analytical grade), cadmium as $\mathrm{CdCl}_{2} \cdot 2.5 \mathrm{H}_{2} \mathrm{O}$ (analytical grade) and lead as $\mathrm{PbCl}_{2}$ (analytical grade) were purchased from Sinopharm Chemical Reagent Co., Ltd.

\subsection{Exposure concentrations}

An exposure concentration which is lower than $\mathrm{LC}_{50}$ is considered as sub-lethal concentration. In algal toxicity test, the $\mathrm{LC}_{50}$ value is affected by the initial cellular density, culture medium, temperature condition, etc., and even a small alteration in those conditions may give rise to a different $\mathrm{LC}_{50}$ value, even if the same algae and metal are used. $\mathrm{LC}_{50}$ values referenced from previous experiments showed discrepancies, so exposure concentrations were determined by a preliminary experiment in this study.

The preliminary experiment showed that the $96 \mathrm{~h}-\mathrm{LC}_{50}$ of $\mathrm{Cu}^{2+}$ for $C$. vulgaris was approximately $10 \mu \mathrm{mol} \mathrm{L}{ }^{-1}$. Former studies reported that $\mathrm{Cu}$ was the most toxic one among the five heavy metals, so it can be inferred that the 96 $\mathrm{h}-\mathrm{LC}_{50}$ of the other four metals should be above $10 \mu \mathrm{mol}$ $\mathrm{L}^{-1}$. For the purpose of comparison, exposure concentrations were kept exactly the same for all metals, at $0.05,0.5$ and $5 \mu \mathrm{mol} \mathrm{L}{ }^{-1}$. In addition, the results shown in section 2.1 manifested that the percentage of inhibition (PI) was below $50 \%$ in all conditions after $96 \mathrm{~h}$ under the setting concentrations. Hence, the exposure concentrations are indeed sub-lethal concentrations.

\subsection{Algae pre-cultivation}

Because $\mathrm{Cu}^{2+}$ and $\mathrm{Zn}^{2+}$ are both contained in BG11 medium, it is necessary to pre-cultivate $C$. vulgaris in a medium without $\mathrm{Cu}^{2+}$ or $\mathrm{Zn}^{2+}$ to control the experimental concentrations of the metals.

In a BG11 medium, the concentration of $\mathrm{CuSO}_{4} \cdot 5 \mathrm{H}_{2} \mathrm{O}$ and $\mathrm{ZnSO}_{4} \cdot 7 \mathrm{H}_{2} \mathrm{O}$ is $0.079 \mathrm{mg} \mathrm{L}^{-1}$ and $0.222 \mathrm{mg} \mathrm{L}^{-1}$, respectively, which is approximately $0.31 \mu \mathrm{mol} \mathrm{L} \mathrm{L}^{-1}$ for $\mathrm{Cu}^{2+}$ and $0.77 \mu \mathrm{mol} \mathrm{L}^{-1}$ for $\mathrm{Zn}^{2+}$. When diluted, the concentration of $\mathrm{Cu}^{2+}\left(\mathrm{Zn}^{2+}\right)$ in the medium reduced to $0.01(0.02) \mu \mathrm{mol}$ $\mathrm{L}^{-1}$, which represented $20 \%(40 \%)$ of a $0.05 \mu \mathrm{mol} \mathrm{L} \mathrm{L}^{-1}$ solution. Considering that both elements are required for the algae's growth, and taking into account the enrichment of the algae, the concentration will be further reduced over time. However, the concentrations of $\mathrm{Cu}^{2+}$ and $\mathrm{Zn}^{2+}$ remaining in the medium after dilution may still exert a slight effect on the treatments at the lowest exposure concentration. As a result, $C$. vulgaris was pre-cultivated in a medium without $\mathrm{Cu}^{2+}$ or $\mathrm{Zn}^{2+}$. Our former study showed that the influence of phosphorus was eliminated by 3 days' precultivation in a medium without phosphorus. Therefore, the time for pre-cultivation in this study was set at $3 \mathrm{~d}$ as well. Before the formal exposure experiment, $C$. vulgaris was diluted twice, including a 10 -fold dilution before precultivation followed by a 3-4 fold dilution. The effects of the dilution, combined with the consumption of $\mathrm{Cu}^{2+}$ and $\mathrm{Zn}^{2}$ by $C$. uvlgaris during growth, significantly reduced the concentration of the metals, even to the point of nondetection. From our point of view, pre-cultivation eliminated the effect of any remaining $\mathrm{Cu}^{2+}$ and $\mathrm{Zn}^{2+}$ from the 0.05 $\mu \mathrm{mol} \mathrm{L}{ }^{-1}$ treatment.

\subsection{Experiment design}

C. vulgaris was cultivated in $250 \mathrm{~mL}$ flask and exposed to $\mathrm{Cu}, \mathrm{Cr}, \mathrm{Zn}, \mathrm{Cd}$ and $\mathrm{Pb}$ at given concentrations of $0.05,0.5$ and $5 \mu \mathrm{mol} \mathrm{L}{ }^{-1}$, with a blank included for each of the experimental groups. Three parallels were set to ensure the repeatability of each sample concentration. The alga tested 
was in exponential phase with a density of $2 \times 10^{6}$ cells $\mathrm{mL}^{-1}$. The $C$. vulgaris exposed to $\mathrm{Cu}$ and $\mathrm{Zn}$ was pre-cultivated for $3 \mathrm{~d}$. The treatments were not aerated because shaking 2-3 times every day introduced the possibility of keeping the algae in vigor. Chlorophyll fluorescence and biomass were measured every $24 \mathrm{~h}$ over the duration of $96 \mathrm{~h}$.

\subsection{Algal growth analysis}

Growth was measured by a microplate reader (Model-680, Bio-Rad) at $450 \mathrm{~nm}$ (optical density) and then converted into unit of biomass (cells $\mathrm{mL}^{-1}$ ). The inhibition, $P$, is calculated using the following formula:

$$
P=\frac{\lg N_{t \text { control }}-\lg N_{t}}{\lg N_{t \text { control }}-\lg N_{0 \text { control }}},
$$

where $N_{0}$ control is the biomass of control at time 0 , and $N_{t \text { control }}$ and $N_{t}$ are the biomass of control and treatment at time $t$.

\subsection{Chlorophyll fluorescence analysis}

The maximal quantum yield of PSII $\left(F_{\mathrm{v}} / F_{\mathrm{m}}\right)$ was chosen to indicate the photosynthetic capacity of $C$. vulgaris and measured by MAXI-Imaging-PAM (WALZ, Germany) after 25 min dark adaptation. $F_{\mathrm{v}} / F_{\mathrm{m}}$ was calculated by $F_{0}$ (the minimal level of fluorescence) and $F_{\mathrm{m}}$ (the maximal level of fluorescence), which were directly measured and where $F_{\mathrm{v}} / F_{\mathrm{m}}=\left(F_{\mathrm{m}}-F_{0}\right) / F_{\mathrm{m}}$.

\subsection{Data analysis}

Data were analyzed by the program SPSS 16.0 and Excel 2010 for Windows.

\section{Results and discussions}

\subsection{Effects of five metals on the growth}

The effects of five heavy metals on the growth of C. vulgaris are shown in Figure 1. There was no significant effect under the $0.05 \mu \mathrm{mol} \mathrm{L}{ }^{-1}$ treatment when $\mathrm{Cd}$ or $\mathrm{Zn}$ was added to the medium $(P>0.05)$, though an inhibiting effect was found when the same concentration of $\mathrm{Cu}, \mathrm{Cr}$ or $\mathrm{Pb}$ was added $(P<0.05)$. However, biomass were lower than the blank in all cases when exposure concentration increased to $5 \mu \mathrm{mol} \mathrm{L}^{-1}$, indicating that specific concentration had an inhibiting impact on algal growth. The inhibition effect

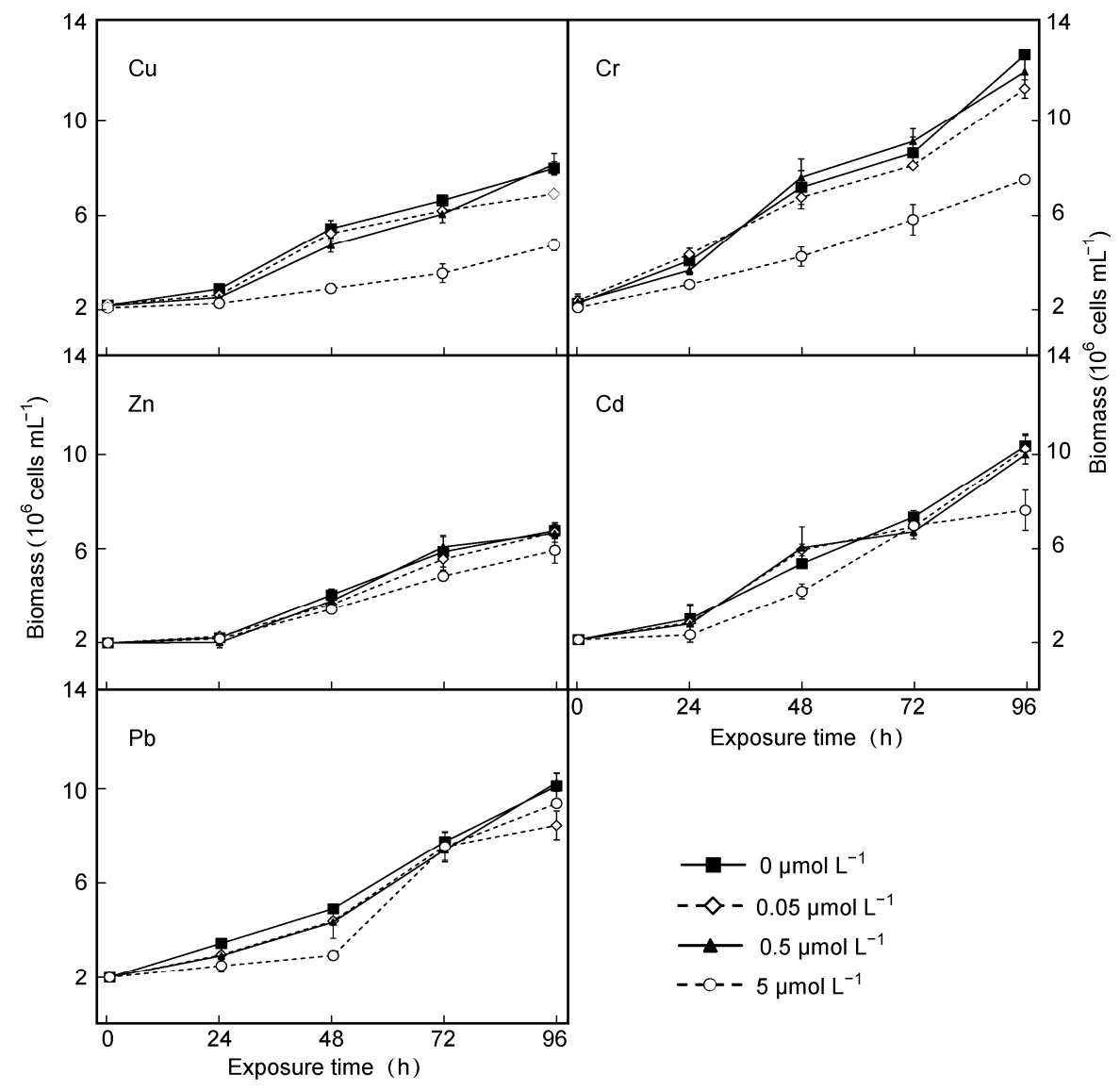

Figure 1 Effects of $\mathrm{Cu}, \mathrm{Cr}, \mathrm{Zn}, \mathrm{Cd}$ and $\mathrm{Pb}$ treatments $\left(0,0.05,0.5\right.$ and $\left.5 \mu \mathrm{mol} \mathrm{L}{ }^{-1}\right)$ on the growth of Chlorella vulgaris. 
became weaker with the increase of exposure time. For example, the percentages of inhibition (PI) under $5 \mu \mathrm{mol}$ $\mathrm{L}^{-1} \mathrm{Cu}$ were $85.5 \%, 67.8 \%, 55.05 \%$ and $38.3 \%$ after exposure times of 24, 48, 72 and $96 \mathrm{~h}$, showing a downward trend.

As shown in Table 1, the toxic effects of heavy metals were dependent on both concentration and exposure time. The growth of $C$. vulgaris was significantly affected by metal concentration and exposure time together with their interaction in the tests of $\mathrm{Cu}, \mathrm{Cr}, \mathrm{Zn}$ and $\mathrm{Pb}(P<0.05)$. As for $\mathrm{Cd}$, metal concentration and exposure time also influenced algal growth rate, but their interaction showed no effect $(P=0.055)$.

Qian et al. [5] found that the $\mathrm{EC}_{50}$ value of $\mathrm{Cu}$ was lower than that of $\mathrm{Cd}$ with respect to the growth of $C$. vulgaris, suggesting that $\mathrm{Cu}$ was more toxic than $\mathrm{Cd}$. A similar result was found by Ismail et al. [9] when Isochrysi galbana, Tetraselmis tetrahele and Tetraselmis sp. were used as test algae. Franklin et al. [11] recorded the toxic sequence as $\mathrm{Cu}>\mathrm{Cd}>\mathrm{Zn}$ for Chlorella sp. while Liang et al. [12] reported the sequence as $\mathrm{Cd}>\mathrm{Cu}>\mathrm{Zn}$ for Phaeodactylum tricornutum. Obviously, the toxic rank for different metals is not static and depends on the species of algae. Our results revealed that $\mathrm{Cu}$ was the most toxic of the five metals, but the rank varied as the exposure time changed. The toxic sequence after $24 \mathrm{~h}$ was $\mathrm{Cu}>\mathrm{Cd}>\mathrm{Pb}>\mathrm{Cr}>\mathrm{Zn}$, but after $96 \mathrm{~h}$, it changed to $\mathrm{Cu}>\mathrm{Cr}>\mathrm{Cd}>\mathrm{Zn}>\mathrm{Pb}\left(5 \mu \mathrm{mol} \mathrm{L}{ }^{-1}\right.$ treatments were used to compare). Considering that $\mathrm{Cu}$ and $\mathrm{Zn}$ are indispensable elements for algae growth, the difference threshold might be the reason why $\mathrm{Cu}$ was more poisonous than $\mathrm{Zn}$. As to other three metals, the difference in ranking order may arise from differential tolerances when under stress or from the sequence during detoxification.

Table 1 2-way-ANOVA on the biomass of Chlorella vulgaris exposed to different metal concentrations for different time

\begin{tabular}{clrc}
\hline Metal & \multicolumn{1}{c}{ Factor } & \multicolumn{1}{c}{$F$} & $P$-level \\
\hline $\mathrm{Cu}$ & Concentration $\left(\mu \mathrm{mol} \mathrm{L}{ }^{-1}\right)$ & 180.848 & $P<0.001$ \\
& Exposure time $(\mathrm{h})$ & 796.695 & $P<0.001$ \\
& Concentration $\times$ time & 26.094 & $P<0.001$ \\
$\mathrm{Cr}$ & Concentration $\left(\mu \mathrm{mol} \mathrm{L}{ }^{-1}\right)$ & 111.172 & $P<0.001$ \\
& Exposure time $(\mathrm{h})$ & 765.912 & $P<0.001$ \\
& Concentration $\times$ time & 14.372 & $P<0.001$ \\
$\mathrm{Zn}$ & Concentration $\left(\mu \mathrm{mol} \mathrm{L} \mathrm{L}^{-1}\right)$ & 9.218 & $P<0.001$ \\
& Exposure time $(\mathrm{h})$ & 547.360 & $P<0.001$ \\
& Concentration $\times$ time & 2.010 & $P=0.049$ \\
$\mathrm{Cd}$ & Concentration $\left(\mu \mathrm{mol} \mathrm{L} \mathrm{L}^{-1}\right)$ & 9.330 & $P<0.001$ \\
& Exposure time $(\mathrm{h})$ & 364.299 & $P<0.001$ \\
& Concentration $\times$ time & 1.965 & $P=0.055$ \\
$\mathrm{~Pb}$ & Concentration $\left(\mu \mathrm{mol} \mathrm{L} \mathrm{L}^{-1}\right)$ & 15.888 & $P<0.001$ \\
& Exposure time $(\mathrm{h})$ & 979.575 & $P<0.001$ \\
& Concentration $\times$ time & 5.499 & $P<0.001$ \\
\hline
\end{tabular}

\subsection{Effects of five metals on the photosynthesis}

$F_{\mathrm{v}} / F_{\mathrm{m}}$ was used to indicate the influences of different metals on the photosynthesis of $C$. vulgaris. The variations of $F_{\mathrm{v}} / F_{\mathrm{m}}$ for $C$. vulgaris are shown in Figure 2. Photosynthesis yield declined at first and then rose sharply with the increase of exposure time. The decline can be attributed to both the change of cultivation as well as the state of the algae. Because $C$. vulgaris was diluted to the same initial density for each treatment, a recovery process was required, thus resulting in a lower $F_{\mathrm{v}} / F_{\mathrm{m}}$ over the initial $24 \mathrm{~h}$. With the increase of biomass, the chlorophyll fluorescence absorbed and shaded by the medium also increased, leading to a more reduction of maximum fluorescence $\left(F_{\mathrm{m}}\right)$ compared to minimum fluorescence $\left(F_{0}\right)$, which resulted in a higher $F_{\mathrm{v}} / F_{\mathrm{m}}\left(1-F_{\mathrm{m}} / F_{0}\right)$. Even though, the influence of heavy metals on the quantum yield of PSII can still be distinguished. Chlorophyll fluorescence images were taken of all treatments at the end of their exposure period to display the change of $F_{\mathrm{v}} / F_{\mathrm{m}}$ (Figure 3$) . \quad F_{\mathrm{v}} / F_{\mathrm{m}}$ of $C$. vulgaris in $5 \mu \mathrm{mol} \mathrm{L}^{-1} \mathrm{Cu}$ and $\mathrm{Cr}$ treatments were lower than their corresponding controls, indicating that a suppression of photosynthesis was caused by $\mathrm{Cu}$ and $\mathrm{Cr}$. Figure 3 also shows that $F_{\mathrm{v}} / F_{\mathrm{m}}$ values of the control samples in $\mathrm{Cu}$ and $\mathrm{Zn}$ treatments were relatively lower than those in the other control samples, which was attributed to the lack of necessary $\mathrm{Cu}$ or $\mathrm{Zn}$ in those controls.

No common conclusion could be drawn about the effects of the five metals on the photosynthesis of $C$. vulgaris. Except for $\mathrm{Cd}$, no significant effect was found for the lowest

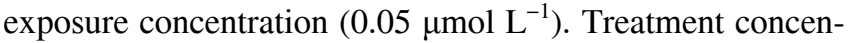
tration of $5 \mu \mathrm{mol} \mathrm{L} \mathrm{L}^{-1}$ showed that $\mathrm{Cu}$ and $\mathrm{Cr}$ reduced the quantum yield of PS II, $\mathrm{Zn}$ and $\mathrm{Cd}$ increased the yield and $\mathrm{Pb}$ displayed no impact. After $96 \mathrm{~h}$ of exposure, the proportion of the maximum quantum yield of PS II promoted by $\mathrm{Zn}$ and $\mathrm{Cd}$ was approximately $10 \%$.

Recent studies regarding photosynthesis have increased due to the development of chlorophyll fluorescence technology and included researches into factors affecting photosynthesis and to what degree these factors affect the photosynthetic process. Few comparisons between studies have been carried out, however. During a study of seven species of marine macroalgae, Bauman et al. [10] found that the chlorophyll fluorescence was reduced by $\mathrm{Cu}, \mathrm{Zn}, \mathrm{Cd}$ and $\mathrm{Cr}$ but was not affected by $\mathrm{Pb}$ under the concentration of 10 $\mu \mathrm{mol} \mathrm{L} \mathrm{L}^{-1}$. Our study found that under a concentration of 5 $\mu \mathrm{mol} \mathrm{L} \mathrm{L}^{-1}$, the quantum yield of PS II was reduced by $\mathrm{Cu}$ and $\mathrm{Cr}$, promoted by $\mathrm{Zn}$ and $\mathrm{Cd}$ and not affected by $\mathrm{Pb}$. The promotion effect was not observed in the previous studies and could be a result of stimulatory effect at low concentrations.

\subsection{Comparison of the effects on the growth and photosynthesis}

In previous studies, the effects of heavy metals on the 


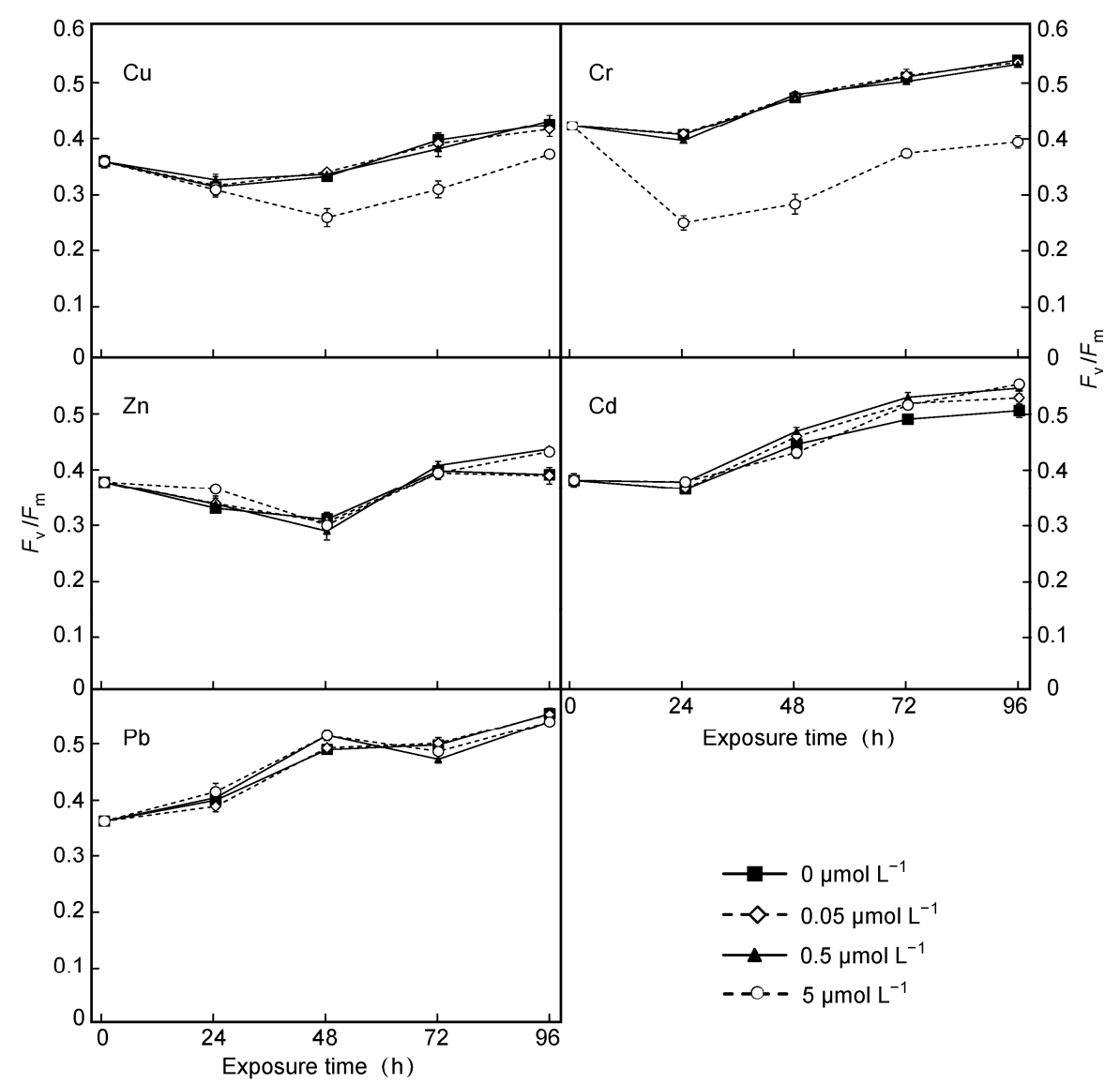

Figure 2 Effects of $\mathrm{Cu}, \mathrm{Cr}, \mathrm{Zn}, \mathrm{Cd}$ and $\mathrm{Pb}$ treatments $\left(0,0.05,0.5\right.$ and $\left.5 \mu \mathrm{mol} \mathrm{\textrm {L } ^ { - 1 }}\right)$ on the photosynthesis of Chlorella vulgaris.

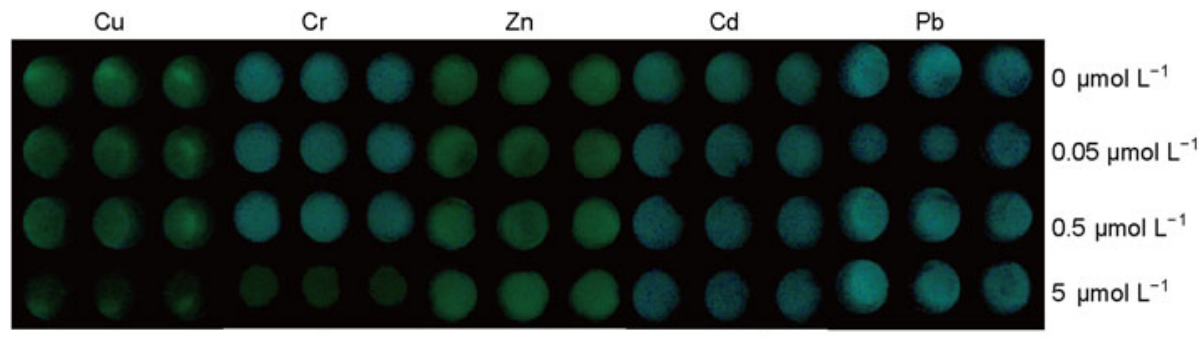

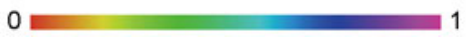

Figure 3 Chlorophyll fluorescence images of Chlorella vulgaris exposed to $\mathrm{Cu}, \mathrm{Cr}, \mathrm{Zn}, \mathrm{Cd}$ and $\mathrm{Pb}$ after $96 \mathrm{~h}$.

growth and photosynthesis have been discussed separately. In our study, a comparison was conducted by analyzing the effects of the five metals on the growth and chlorophyll fluorescence of $C$. vulgaris. Figure 4 shows the impacts of the five metals on the growth at different time, which is represented by PI. When the PI was positive, the effect was regarded as inhibition, with a higher PI indicating a higher toxic level of the metal. Figure 5 shows the influence of five metals on the photosynthesis over time, which is represented by relative $F_{\mathrm{v}} / F_{\mathrm{m}}$ value compared to the corresponding control. When the ratio is above 1 , the effect is considered as promotion, with result less than 1 considered as inhibition.
As shown in Figures 4 and 5, $\mathrm{Cu}$ and $\mathrm{Cr}$ both reduced biomass and chlorophyll fluorescence at the same time. The inhibition upon growth reached a climax within $24 \mathrm{~h}$ in the

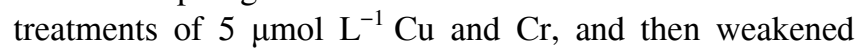
with the increased exposure time. The inhibition on the photosynthesis for $\mathrm{Cr}$ was observed after $24 \mathrm{~h}$ and reached the peak at $48 \mathrm{~h}$. But for $\mathrm{Cu}$, the inhibition was observed after $48 \mathrm{~h}$ and reached the peak at $72 \mathrm{~h}$. As a result, $\mathrm{Cu}$ was found to be more toxic than $\mathrm{Cr}$ when evaluated by the growth, but $\mathrm{Cr}$ was found to be the more toxic when evaluated by the photosynthesis. It also indicates that the effects upon chlorophyll fluorescence showed a lagged response comparing to the growth rate, although the effects of 

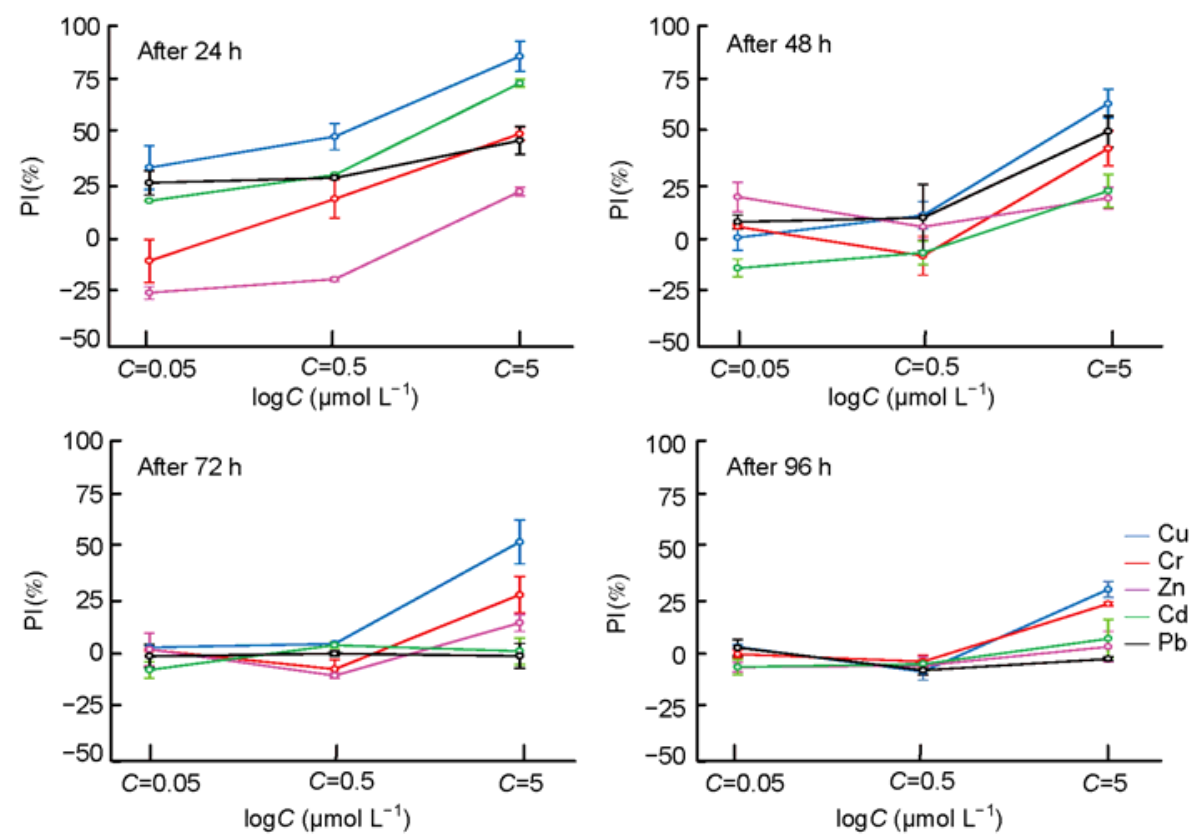

Figure 4 PIs of different treatments on the growth of Chlorella vulgaris in different time (PI means the percentage of inhibition).
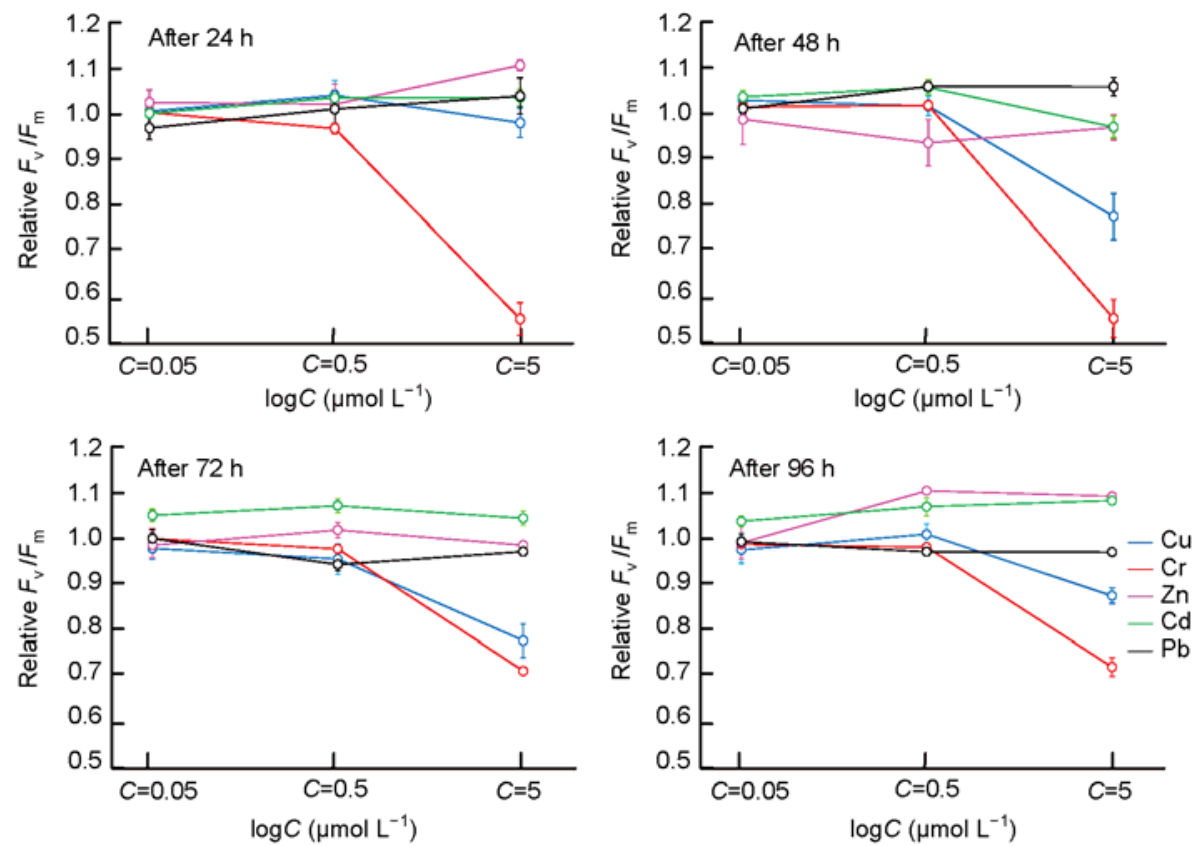

Figure 5 Effects of different treatments on the $F_{\mathrm{v}} / F_{\mathrm{m}}$ of Chlorella vulgaris at different times.

inhibition on the growth and photosynthesis both decreased over time due to the adaptive mechanism of $C$. vulgaris.

$\mathrm{Zn}$ and $\mathrm{Cd}$ reduced biomass but enhanced the quantum yield of photochemistry. Similar to $\mathrm{Cu}$, the effect of $\mathrm{Cd}$ on algae growth culminated quickly and then declined. At $5 \mu \mathrm{mol} \mathrm{L}{ }^{-1}$, the suppression effect of $\mathrm{Zn}$ reached a peak at $48 \mathrm{~h}$. Cd was more toxic than $\mathrm{Zn}$ within $48 \mathrm{~h}$, but became less toxic than $\mathrm{Zn}$ after exposure for a longer time. Meanwhile, a significant promoting effect on the photosynthesis by $\mathrm{Zn}$ and $\mathrm{Cd}$ was observed after $72 \mathrm{~h}$. Overall, it can be concluded that the mechanisms of these two metals upon growth and photosynthesis were totally different because a suppression of growth and a promotion of photosynthesis were found simultaneously.

$\mathrm{Pb}$ reduced biomass, with the metal presenting a high inhibition effect at first but rapidly declining thereafter. Chlorophyll fluorescence was not affected by $\mathrm{Pb}$. Hence, sub-lethal concentrations of $\mathrm{Pb}$ did not produce a significant toxic effect for $C$. vulgaris within $96 \mathrm{~h}$.

Perales-Vela et al. [13] reported that the growth of 
Table 2 Comparison of effects on the growth and photosynthesis of Chlorella vulgaris by different metals under different concentrations

\begin{tabular}{ccccc}
\hline \multirow{2}{*}{ Metal } & Factor & \multicolumn{3}{c}{ Exposure concentration $\left(\mu \mathrm{mol} \mathrm{L}^{-1}\right)$} \\
\cline { 3 - 5 } & & 0.05 & 0.5 & $-(P<0.001)$ \\
$\mathrm{nu}$ & Growth & $-^{\mathrm{a})}(P<0.001)$ & $-(P=0.002)$ & $-(P<0.001)$ \\
& Photosynthesis & $0^{\mathrm{b}}(P=0.877)$ & $0(P=0.657)$ & $-(P<0.001)$ \\
$\mathrm{Cr}$ & Growth & $-(P=0.013)$ & $0(P=0.826)$ & $-(P<0.001)$ \\
& Photosynthesis & $0(P=0.421)$ & $0(P=0.165)$ & $+(P<0.001)$ \\
$\mathrm{Zn}$ & Growth & $0(P=0.090)$ & $0(P=0.255)$ & $-(P<0.001)$ \\
& Photosynthesis & $0(P=0.910)$ & $0(P=0.281)$ & $+(P<0.001)$ \\
$\mathrm{Cd}$ & Growth & $0(P=0.485)$ & $+(P<0.001)$ & $-(P<0.001)$ \\
& Photosynthesis & $+(P<0.001)$ & $0(P=0.058)$ & $0(P=0.084)$ \\
\hline
\end{tabular}

a) - means inhibition; b) 0 means no significant effect; c) + means promotion.

Scenedesmus incrassatulus was much more sensitive than its photosynthetic electron transport when the alga was exposed to $\mathrm{Cu}^{2+}$ at sub-lethal concentrations of $0-3.145$ $\mu \mathrm{mol} \mathrm{L}^{-1}$. A similar result was found in our experiments when $C$. vulgaris was exposed to $\mathrm{Cu}$ and $\mathrm{Cr}$. Because it is very important to balance fundamental functions to be survival, algae tend to sacrifice its growth to maintain essential photosynthesis processes under stress [14]. Therefore, the exposure of heavy metals might not affect photosynthesis as quickly as it does growth, as was shown in exposure experiments of $\mathrm{Cu}$ and $\mathrm{Cr} . \mathrm{Cu}^{2+}$ can oxidize membrane lipids, resulting in an increased quantity of active oxygen which can break the thylakoid layer structure, thus affecting photosynthesis of the plant $[15,16]$. The results showed that photosynthesis rates remained at normal levels longer than growth rates did under the stress of $\mathrm{Cu}^{2+}$. So, it may be necessary for heavy metals to get into the cell before they can affect the photosynthesis of algae. Thus, it can be speculated that a phenomenon may be occurring whereby growth is partially restrained but photosynthesis continues normally. Andrade et al. [17] observed a self-protection mechanism against $\mathrm{Cd}$ and $\mathrm{Pb}$ toxicity in which the cell walls in brown algae overproduced polysaccharides. Thus, heavy metals may increase the production of polysaccharides, which ask for an increase of photochemistry efficiency since photosynthesis is the key process for transferring solar energy into chemical energy, with the result being a stimulation effect upon the algae.

Comparison of the effects of $\mathrm{Cu}, \mathrm{Cr}, \mathrm{Zn}, \mathrm{Cd}$ and $\mathrm{Pb}$ on the growth and photosynthesis of $C$. vulgaris is listed in Table 2. It can be inferred that the different factors effecting growth and photosynthesis are not causally related. Nielsen H D and Nielsen S L [18] found the effect of $\mathrm{Cu}^{2+}$ on the photosynthesis of Fucus serrantus was unrelated to its effect on growth inhibition. They recognized $\mathrm{Cu}^{2+}$ could inhibit the growth rate of algae by affecting the growth process directly, and the rate of growth inhibition caused by $\mathrm{Cu}^{2+}$ was not related to any effects that $\mathrm{Cu}^{2+}$ might have upon photosynthesis. As a result, it has been shown that growth and photosynthesis are independent processes unrelated to each other. Thus, it is necessary to take both the growth process and the photosynthesis process into account when estimating the ecological risk of a toxicant, especially under sub-lethal concentrations.

\section{Conclusions}

All the five metals inhibited the growth of $C$. vulgaris, and the effects were both dose-dependent and time-dependent. In treatments using PIs of $5 \mu \mathrm{mol} \mathrm{L}{ }^{-1}$, the toxic order was $\mathrm{Cu}>\mathrm{Cd}>\mathrm{Pb}>\mathrm{Cr}>\mathrm{Zn}$ after $24 \mathrm{~h}$ but changed to $\mathrm{Cu}>\mathrm{Cr}>\mathrm{Cd}>$ $\mathrm{Zn}>\mathrm{Pb}$ after $96 \mathrm{~h}$. Unlike the effects on the growth, the impacts on the photosynthesis were more complicated. $\mathrm{Cu}$ and $\mathrm{Cr}$ reduced the quantum yield of PSII while $\mathrm{Zn}$ and $\mathrm{Cd}$ increased the yield, with $\mathrm{Pb}$ showed a negligible impact. Thus, the effects of heavy metals on the growth and photosynthesis of $C$. vulgaris are independent to each other and are not causally related.

In general, $\mathrm{Cu}$ and $\mathrm{Cr}$ were the most harmful metals among the five heavy metals investigated, even at sub-lethal concentrations. Although heavy metals had differential influences on the growth and photosynthesis, heavy metals at sub-lethal concentrations can reduce the algal growth rate, which indicates that the presence of all five metals should be paid attention to, even at sub-lethal concentrations.

This work was supported by the Key Program of National Natural Science Foundation of China (41030529), the National Natural Science Founds for Distinguished Young Scholars (40725004), the National Project for Water Pollution Control (2008ZX07103-005-01), the Specific Scientific Research Funds for Environment Protection Commonweal Section of China (20100932) and Doctoral Fund of Ministry of Education of China (20100001110035).

1 Burda K, Kruk J, Schmid G H, et al. Inhibition of oxygen evolution in photosystem II by $\mathrm{Cu}$ (II) ions is associated with oxidation of cytochrome $b_{559}$. Biochem J, 2003, 371: 597-601 
2 Andrade L R, Farina M, Filho G M A. Effects of copper on Enteromorpha flexuosa (Chlorophyta) in vitro. Ecotoxicol Environ Saf, 2004, 58: 117-125

3 Clemens S. Molecular mechanisms of plant metal tolerance and homeostasis. Planta, 2001, 212: 475-486

4 Vignati D A L, Dominik J, Beye M L, et al. Chromium (VI) is more toxic than chromium (III) to freshwater algae: A paradigm to revise?. Ecotoxicol Environ Saf, 2010, 73: 743-749

5 Qian H F, Li J J, Sun L W, et al. Combined effect of copper and cadmium on Chlorella vulgaris growth and photosynthesis-related gene transcription. Aquat Toxicol, 2009, 94: 56-61

6 Sandalio L M, Dalurzo H C, Gómez M, et al. Cadmium-induced changes in the growth and oxidative metabolism of pea plants. J Exp Bot, 2001, 52: 2115-2126

7 Pawlik-Skowroska B. Correlations between toxic $\mathrm{Pb}$ effects and production of $\mathrm{Pb}$-induced thiol peptides in the microalga Stichococcus bacillaris. Environ Pollut, 2002, 119: 119-127

8 Chen L, Zheng Q S, Liu Z P, et al. Effects of different concentrations of copper ion on the growth and chlorophyll fluorescence characteristics of Scendesmus obliquus L. Ecol Environ Sci, 2009, 18: 12311235

9 Ismail M, Phang S M, Tong S L, et al. A modified toxicity testing method using tropical marine microalgae. Environ Monit Assess, 2002, 75: 145-154

10 Baumann H A, Morrison L, Stengel D B. Metal accumulation and toxicity measured by PAM-chlorophyll fluorescence in seven species of marine macroalgae. Ecotoxicol Environ Saf, 2009, 72: 1063-1075
11 Franklin N M, Stauber J L, Lim R P, et al. Toxicity of metal mixtures to a tropical freshwater alga (chlorella $s p$.): The effect of interactions between copper, cadmium, and zinc on metal cell binding and uptake. Environ Toxicol Chem, 2002, 21: 2412-2422

12 Liang Y, Wang S, Feng L X, et al. Effects of heavy metals stress on growth and chlorophyll fluorescence of Phaeodactylum tricornutum. Mar Environ Sci, 2009, 28: 374-382

13 Perales-Vela H V, González-Moreno S, Montes-Horcasitas C, et al. Growth, photosynthetic and respiratory responses to sub-lethal copper concentrations in Scenedesmus incrassatulus (Chlorophyceae). Chemosphere, 2007, 67: 2274-2281

14 Hagemeyer J. Ecophysiology of plant growth under heavy metal stress. In: Prasad M N V, Hagemeyer J, eds. Heavy Metal Stress in Plants. Berlin: Springer, 1999. 157-181

15 Vassilev A, Lidon F, Campos P S, et al. Cu-induced changes in chloroplast lipids and photosystem II activity in barley plants. Bulg J Plant Physiol, 2003, 29: 33-43

16 Pätsikkä E, Aro E M, Tyystjärvi E. Mechanism of copper-enhanced photoinhibition in thylakoid membranes. Physiol Plant, 2001, 113: $142-150$

17 Andrade L R, Leal R N, Noseda M, et al. Brown algae overproduce cell wall polysaccharides as a protection mechanism against the heavy metal toxicity. Mar Pollut Bull, 2010, 60: 1482-1488

18 Nielsen H D, Nielsen S L. Photosynthetic responses to $\mathrm{Cu}^{2+}$ exposure are independent of light acclimation and uncoupled from growth inhibition in Fucus serratus (Phaeophyceae). Mar Pollut Bull, 2005, 51: 715-721

Open Access This article is distributed under the terms of the Creative Commons Attribution License which permits any use, distribution, and reproduction in any medium, provided the original author(s) and source are credited. 